\title{
The size of signal detection and emission organs in a synchronous firefly: sexual dimorphism, allometry and assortative mating
}

\author{
Tania López-Palafox ${ }^{1}$, Rogelio Macías-Ordóñez ${ }^{2}$, Carlos R Cordero ${ }^{\text {Corresp. } 3}$ \\ 1 Posgrado en Ciencias Biomédicas, Instituto de Ecología, Universidad Nacional Autónoma de México, Mexico City, Mexico \\ 2 Instituto de Ecología A.C., Xalapa, Veracruz, México \\ 3 Departamento de Ecología Evolutiva, Instituto de Ecología, Universidad Nacional Autónoma de México, Mexico City, México \\ Corresponding Author: Carlos R Cordero \\ Email address: cordero@ecologia.unam.mx
}

The size of the organs responsible for emitting and detecting sexual communication signals is a likely target for selection. Communication via bioluminescent signals in synchronous fireflies is a promising model to test hypotheses regarding differences between males and females in the effect of the size of signal emission and detection organs on fitness components. Synchronous firefly species congregate in large numbers during the mating season, displaying bioluminescent signals aimed at potential mates during relatively short nightly periods. Operational sex ratios are male-biased and, thus, the so-called typical sex roles (indiscriminate males and choosy females) are expected to evolve. We studied the synchronous firefly Photinus palaciosi, a species that during the mating season congregates in forests of central Mexico offering a magnificent natural show that attracts numerous tourists. P. palaciosi females have reduced wings (brachyptery) and cannot fly. Our field study tested the hypothesis that the male-biased operational sex ratio and the short daily mating period result in strong male-male competition that selects for males with larger lanterns and larger eyes, and against male mate choice, whereas female-female mate competition is absent and, thus, no selection on lantern or eye size is expected. Even though lantern, eye or body size do not predict the probability of being found in copula for either sex, sexual dimorphism in these features, along with allometric slopes of lantern size and assortative mating in terms of relative lantern size, support not only the hypothesis of intense sexual selection among males, but the possibility of subtle mechanisms of sexual selection among females. Trade-offs between investment in signaling (lanterns) versus detection (eyes) structures, or with pressures different from sexual selection such as those imposed by predators, are also likely to be important in shaping the evolution of sexual signaling in these fireflies. 


\section{The size of signal detection and emission organs in a synchronous}

\section{2 firefly: sexual dimorphism, allometry and assortative mating}

4 Short title: Lantern and eye size in firefly mating

5

6

7 Tania López-Palafox ${ }^{1}$, Rogelio Macías-Ordóñez ${ }^{2}$, Carlos Cordero ${ }^{3}$

$9{ }^{1}$ Posgrado en Ciencias Biomédicas, Instituto de Ecología, Universidad Nacional Autónoma de

10 México, Ciudad de México, México

$11{ }^{2}$ Instituto de Ecología A.C., Xalapa, Veracruz, México

$12{ }^{3}$ Departamento de Ecología Evolutiva, Instituto de Ecología, Universidad Nacional Autónoma

13 de México, Circuito exterior s/n, Ciudad Universitaria, Coyoacán 045, Ciudad de México,

14 México

15

16 Corresponding author:

17 Carlos Cordero

18 E-mail address: cordero@ecologia.unam.mx 


\section{ABSTRACT}

20 The size of the organs responsible for emitting and detecting sexual communication signals is a

21 likely target for selection. Communication via bioluminescent signals in synchronous fireflies is

22 a promising model to test hypotheses regarding differences between males and females in the

23 effect of the size of signal emission and detection organs on fitness components. Synchronous

24 firefly species congregate in large numbers during the mating season, displaying bioluminescent

25 signals aimed at potential mates during relatively short nightly periods. Operational sex ratios are

26 male-biased and, thus, the so-called typical sex roles (indiscriminate males and choosy females)

27 are expected to evolve. We studied the synchronous firefly Photinus palaciosi, a species that

28 during the mating season congregates in forests of central Mexico offering a magnificent natural

29 show that attracts numerous tourists. P. palaciosi females have reduced wings (brachyptery) and

30 cannot fly. Our field study tested the hypothesis that the male-biased operational sex ratio and

31 the short daily mating period result in strong male-male competition that selects for males with

32 larger lanterns and larger eyes, and against male mate choice, whereas female-female mate

33 competition is absent and, thus, no selection on lantern or eye size is expected. Even though

34 lantern, eye or body size do not predict the probability of being found in copula for either sex,

35 sexual dimorphism in these features, along with allometric slopes of lantern size and assortative

36 mating in terms of relative lantern size, support not only the hypothesis of intense sexual

37 selection among males, but the possibility of subtle mechanisms of sexual selection among

38 females. Trade-offs between investment in signaling (lanterns) versus detection (eyes) structures,

39 or with pressures different from sexual selection such as those imposed by predators, are also

40 likely to be important in shaping the evolution of sexual signaling in these fireflies. 


\section{INTRODUCTION}

43 Communication between males and females is a fundamental element of the mating biology of 44 most animals (Darwin, 1871; Maynard Smith \& Harper 2003; Rosenthal, 2017). There is a great

45 variety of organs, newly evolved or specialized via sexual selection, for the emission and 46 reception of sexual signals (Darwin, 1871; Rosenthal, 2017; Elgar et al., 2019). A fascinating

47 example of sexual communication involving vision is that of nocturnal fireflies (Lloyd, 1979;

48 Lewis, 2016). In these insects, adults of many species possess an organ specialized for the 49 emission of light known as lantern. Typically, males fly searching for females, emitting speciesand sex-specific flashing patterns that are involved in mate choice, while females emit glows or flashes in response (Lloyd, 1979; Lewis \& Cratsley, 2008; Lewis, 2016; Stanger-Hall et al., 2018). If a successful dialogue is established, the male alights, contacts the female and a closerange courtship ensues (Lewis \& Cratsley, 2008; Stanger-Hall et al., 2018). (Lewis et al., 2004; Lewis \& Cartsley, 2008), it is reasonable to propose that signal intensity, and thus the sizes of the lantern and of the eyes are also important traits influencing the efficiency of

57 sexual communication in fireflies (Vencl \& Carlson, 1998; Crastley \& Lewis, 2003, 2005;

Demary et al., 2006; Lau \& Meyer-Rochow, 2006). Larger lanterns may increase signal

transmission distance (Demary et al., 2006), whereas larger eyes are correlated with smaller interommatidial angles that may help improve visual resolution and distance perception (Lewis et al., 2004), as well as capture more photons thus helping vision in low-light environments

62 (Warrant \& Dacke, 2011; Stanger-Hall et al., 2018). Somewhat surprisingly, studies on the relationship between signal-emission organ size and mating success in fireflies are scant and

64 their results are inconsistent. While some studies in non-synchronic fireflies detected an effect of 
65 male lantern size on mating success and female responses in a high-density population of

66 Photinus pyralis (Vencl \& Carlson, 1998) and in P. ignitus (Crastley \& Lewis, 2003, 2005),

67 another study found that female mating decisions in the non-synchronic $P$. greeni are not

68 influenced by lantern size (Demary et al., 2006). The effects of signal-detection organ (eyes) size

69 on fitness components of both sexes, and of signal emission organ size on female fitness

70 components have not been studied in fireflies (but see Crastley \& Lewis, 2005).

71

In this context, the static allometry of sexual characters (i.e. variation of their relative size

72 among the size range of adults in the population) involved in courtship may be of particular

73 interest. Selection is expected to optimize relative size of any organs depending on their

74 reproductive payoff given each individual's body size. Unlike sexually dimorphic characters

75 involved in intra-sexual agonistic signaling (usually among males) in which larger individuals

76 are expected to show disproportionally larger traits (i.e. positive allometry), the size of sexually

77 dimorphic signaling characters involved in courtship are expected to be more frequently either

78 proportional to body size (i.e. isometry) or even relatively smaller in larger individuals (i.e.

79 negative allometry) (Eberhard et al., 2018). The reason to expect these patterns are diverse, but

80 in general the payoff of relatively larger traits for larger individuals is high when they are

81 involved in agonistic interactions in which body size is a good predictor of fight outcome, thus

82 selecting for conflict resolution prior to engaging in costly or dangerous fights. In male-female

83 reproductive interactions, however, the conditions are much more variable. In many cases

84 selection for "honest" signals accurately reflecting male body size would result in isometry,

85 while in others relatively smaller organs in large males (i.e. negative allometry) result in high

86 payoffs if male quality is not directly related to body size (Eberhard et al., 2018). Furthermore, 
87 the allometry of sexual organs involved in receiving rather than emitting signals, as well as

88

89

90

92

94 sexual differences in allometry, have seldom been explored.

Synchronous flashing fireflies are good subjects to study hypotheses on the effects of the size and allometry of the organs involved in sexual communication on fitness components because in these species the density of signaling males is very large, nightly mating periods are short and the operational sex ratio is male biased, resulting in intense competition between males, likely absence of female-female mate competition, and plenty of opportunities for female choice (Lloyd, 1979; Lewis, 2016). We can hypothesize that intense male-male competition selects for males with larger lanterns that increase signal transmission distance. Selection would also favor males with larger eyes that increase the amount of photons captured in the night and improve the detection distance of the usually faint glows produced by the relatively scarce females. Larger males, but not females, may have a mating advantage over small males due to direct selection on body size (for example, if larger male size is advantageous when several males alight simultaneously and court a female; Thornhill \& Alcock, 1983) or correlative selection (for example, if selection favors larger lantern size and this measure is positively correlated with body size). In contrast to males, females would be selected to emit flashes of just enough intensity to be perceived by the males, thus no selection for increased lantern size is predicted. In fact, it is even possible that females are selected to produce less intense flashes or glows not only reducing costs, but as a female choice mechanism that allows being detected only by particularly sensitive males, an ability they could inherit to their male offspring (Eberhard, 1996). On the other hand, selection for an increase in eye size should be relaxed in females due to the fact that they are the limiting sex and the large number of potential mates encountered every night, although larger eyes could be advantageous if they increase the ability to detect and 
110 respond to high quality males. Since larger signaling and receiver structures should benefit larger

111 males despite their costs, but would represent also higher costs but no additional benefits for

112 larger females, we could expect steeper allometric slopes for lantern and eye size in males than

113 in females. In this paper, we present the results of a field study aimed at testing some of the

114 predictions derived from these hypotheses.

115 We studied the synchronous Mexican firefly Photinus palaciosi (Zaragoza-Caballero,

116 2012; Zaragoza-Caballero et al., 2020). Using field-collected data, we estimated the relationship

117 between the probability of being found in copula and signal emission (lantern) and signal

118 detection (eyes) organ size, and used these data to test the following predictions: (1) Males with

119 larger lanterns and eyes have higher probability of being found in copula, whereas lantern and

120 eye size in females are not related to their mating probability. (2) Larger males have a higher

121 probability of being found in copula. (3) Males have larger lanterns and larger eyes than females.

122 (4) Lantern and eyes allometric slopes are higher in males than in females, but not higher than 1

123 since they are not involved in male-male agonistic interactions. Finally, (5) there is no assortative

124 mating for lantern, eye or body size due to the lack of intra-female sexual selection or male mate

125 choice under highly male competitive conditions.

126

\section{MATERIALS AND METHODS}

\section{Species studied}

129 P. palaciosi lives in pine-oak-fir forests of central Mexico, in the states of Estado de México,

130 Puebla and Tlaxcala, and its reproductive season goes from June to the beginning of August.

131 Mate searching, courtship and mating occur during approximately ninety minutes every night 
132 starting around 20:30 h, although heavy rainfall prevents flying activity. In the study site (Fig. 1),

133 the municipality of Nanacamilpa de Mariano Arista (Tlaxcala state, México), thousands of males

134 congregate under the canopy of the forest during this period, flying in search of females,

135 frequently synchronizing their flashing and providing a magnificent show that attracts numerous

136 tourists (Acle Mena et al., 2018). The females cannot fly because they are brachypterous (i.e.

137 their wings are extremely reduced; Fig. 2) (Zaragoza-Caballero, 2012), and they remain

138 stationary in herbs at heights $<60 \mathrm{~cm}$ and glow infrequently during the mating period. The

139 number of sexually receptive females every night is much smaller than that of males and thus the

140 operational sex ratio (OSR) is male biased (personal observation).

\section{Sample collection}

142 Samples of males and females found in copula or solitary were collected simultaneously by a

143 team of three researchers during the daily mating period (20:30 - 22:00 h GMT-5) in the middle

144 of the 2016 reproduction season (between June 29 and July 14). Signalling males were collected

145 with an entomological net and solitary females and mating couples by hand. Individual mating

146 couples and solitary individuals were kept in Eppendorf vials with absolute alcohol. Captures

147 were made in 10 places (one per night) within a continuous forests in the municipality of

148 Nanacamilpa de Mariano Arista (Table 1; Fig. 1). Our collection was made under the

149 SEMARNAT (Mexican Government) permit SGPA/DGVS/06292/16.

\section{Measurement of phenotypic traits}

151 We obtained three photographs of each firefly (dorsal view, ventral view and a close up of the

152 eyes) with a digital camera (Canon ${ }^{\mathrm{TM}}$ model T3i) mounted on a disection microscope

153 (Olympus ${ }^{\mathrm{TM}}$ model SZH10). The phenotypic measurements were obtained with the NIH ImageJ

154 open access software (National Institutes of Health USA, http://rsb.info.nih.gov.ij/). We 
155 estimated lantern size by measuring the area covered by the lantern in the ventral-view

156 photographs (Fig. 2). Eye size was estimated as the squared difference between maximum

157 eyespan and interocular space (i.e. approximately the sum of the maximum diameter of both

158 eyes) in the eyes close-up photographs (Fig. 2). The reason to square this length was to obtain a

159 variable that would covariate linearly with the rest of the body traits since they were all area

160 measurements. Body size was estimated as the area covered by the elytra of the males in the

161 dorsal view photographs, while in females it was estimated as the area covered by the thorax and

162 the abdomen (Fig. 2). The area covered by the reduced female elytra was also measured to

163 document brachyptery quantitatively, and as an aditional proxy of body size (see below).

\section{Statistical analyses}

165 For predictions 1 and 2, we constructed separate binomial generalized linear models with logit

166 link function for each sex, using mating status ( $0=$ captured alone, $1=$ captured mating) as the

167 binary response variable, and lantern size, eye size (prediction 1), and body size (prediction 2) as

168 explanatory variables, as well as their second order interactions. We simplified the models using

169 backwards stepwise simplification, removing each explanatory variable in order of increasing

170 significance and testing the effect of removing that variable with a chi-squared likelihood ratio

171 test until only terms whose removal leads to worsening of the model remained (Crawley, 2013).

172 A second set of models was constructed and simplified using relative lantern size and relative

173 eye size in order to rule out any effect of colineality among explanatory variables. Relative sizes

174 were estimated dividing trait (lantern or eye) size by body size. A third set of models was

175 constructed and simplified for females in order to rule out the effects of body condition using

176 elytra area as a proxy of body size to construct lantern and eye relative size as explanatory

177 variables. Unlike wing area, abdomen volume (and thus measured abdomen area) may vary 
178 through adulthood depending on body condition, which in turns may depend on water, muscle

179 and fat reserves, and egg load in the case of females (Moya-Laraño et al., 2008). Egg load has

180 been shown to be associated to female weight in a congeneric species of brachypterous females

181 (Wing, 1989).

182

For prediction 3, we performed a simple linear model for each morphological trait (body

183 size, elytra size, lantern size, lantern relative size, eye size and eye relative size) as dependent

184 variable, and sex as the only explanatory variable. Although we had no prediction for body size

185 sexual dimorphism, and elytra size dimorphism is so large that does not require a statistical test,

186 we included these variables in the analyses for descriptive purposes. For prediction 4 we

187 estimated the slope of log-log relationships between lantern size or eye size and body size using

188 ordinary least squares (Kilmer \& Rodriguez, 2016). As described above for prediction 1, a

189 second set of analyses was performed for females using elytra area instead of body size in order

190 to rule out effects of body condition. In order to compare slopes statistically, 95\% confidence

191 intervals were generated for each allometric slope using bootstrap resampling with 10,000

192 randomizations (Crawley, 2013)

193 For prediction 5, we only used individuals captured in copula and tested assortative

194 mating using linear models relating morphological traits (lantern size, lantern relative size, eye

195 size, eye relative size or body size) of males and their respective female mates. As described

196 above for predictions 1 and 3, female elytra area was included as proxy of female body size in

197 order to rule out effects of body condition.

198 We carried out these analyses in R software, version 3.6.3 (R Core Team, 2020) using the

199 R Studio interface ( $R$ Studio Team, 2016). The script used for analyses and the databases with all

200 data can be found as supplementary material (Files S1-S3). 
201

202 RESULTS

203 General observations

204 We sampled 93 females (51 solitary and 42 in copula) and 113 males (71 solitary and 42 in

205 copula). Two copulating females were not included in the analyses because the posture they had

206 after fixation in alcohol prevented obtaining correct measurements.

207 Phenotypic traits and the probability of capture during mating

208 We did not find support for predictions 1 or 2 . Neither body size nor any of the morphological

209 traits associated to signal emission (lantern size, lantern relative size) or reception (eye size or

210 eye relative size), nor their statistical interactions, showed a significant association with the

211 probability of being captured single or mating for either sex (Table 2).

\section{Sexual dimorphism}

213 Males are significantly larger than females, and as could be expected given the brachypterous

214 morphology of females, male wing area is also significantly larger (Table 3). We found partial

215 support for prediction 3. As predicted, males have significantly larger lanterns than females in

216 terms of absolute and relative size. Interestingly however and contrary to our prediction, they

217 have significantly smaller eyes than females in terms of absolute and relative size.

\section{Static allometry}

219 As predicted, the slope of male lantern size allometry was significantly higher than the slope of 220 female lantern size allometry, but not significantly higher than 1 (Table 4, Fig. 3A,C,E). In

221 contrast, eye size allometry was not significantly different from 0 in males or females, and its 
222 relative size varied widely along body size ranges in both sexes (Fig. 3B,D,F). In other words,

223 lantern relative size is constant along the male size range, but in females lantern relative size

224 decreases somewhat towards larger individuals. On the other hand, eye size does not covary with

225 body size in either sex.

\section{Assortative mating}

227 Support for prediction 5 was also partial. We found no correlation between male and female

228 traits in most of the variables (Table 5), but we did find a significant association between male

229 and female relative lantern size when the effect of body condition was removed using the area of

230 female elytra to estimate relative lantern size (Fig 4).

231

232 DISCUSSION

233 In this paper we tested the hypothesis that in synchronous fireflies the male biased operational

234 sex ratios and the short nightly mating period result in strong male-male competition that selects

235 for males with larger signal emission (lantern) and signal detection (eyes) organs, as well as

236 larger body sizes. On the other hand, since in these fireflies male mate choice and female-female

237 competition for mates are expected to be absent, no selection on body and lantern size is

238 expected in females, although intersexual selection (female choice) could favor females with

239 larger signal detection organs (eyes). We did not find support for the predictions that body size,

240 lantern size or eye size would be associated with the probability of being found in copula.

241 However we did find that males are not only larger than females, they have relatively larger

242 lanterns but smaller eyes than females, even adjusting for sexual differences in body size.

243 Furthermore, the allometric slope of lantern size is steeper in males than in females, but the 
244 allometric slope for eye size does not differ from 0 in either sex. Finally, and contrary to our

245 predictions, there is some evidence of assortative mating in terms of lantern relative size.

247 species resembling $P$. palaciosi in that there is "intense competitiveness: aggregations of males

248 regularly attain very high densities", sometimes resulting in several males attempting to mate

249 with the same female (Vencl \& Carlson, 1998), as we have observed in P. palaciosi (personal

250 observations). In contrast to our findings, in P. pyralis the body size (elytral length) and lantern

251 area of males were related to the probability of being found in copula. Interestingly, in this

252 species larger males and males with larger lanterns were more successful when single males

253 courted females (the most common case: $70 \%$ of all matings), but smaller males had an

254 advantage when four or more males simultaneously courted a female "on foot" on her perch

255 (12\% of all matings). According to the authors, these contrasting effects "obscured" the global

256 effect of elytral and lantern length on male mating success (Vencl \& Carlson, 1998). When we

257 collected many of the copulating pairs there was at least one additional male close to the

258 copulating pair, unfortunately we did not make a record of this fact. However, a trade-off similar

259 to that proposed by Vencl \& Carlson (1998) may explain the lack of effects of morphological

260 measures on the probability of being found in copula.

261 Our results, on the other hand, are similar to those obtained in the non-synchronous $P$.

262 greeni, in which the size of lanterns, eyes and body were not related to the probability of males

263 being found alone or in copula (Demary et al., 2006). In this species, as well as in other Photinus

264 species (Branham \& Greenfield, 1996; Crastley \& Lewis, 2003; Demary et al., 2006; Lewis,

265 2016), elements of the flashing pattern are important in determining male mating success.

266 However, elements of the flashing pattern are also important in Photinus ignites, a non- 
267 synchronous firefly in which a significant effect of lantern size and body size on mating success

268 has also been observed (Crastley \& Lewis, 2003, 2005). A study of the effect of the flashing

269 pattern on mating success, and its possible interaction with lantern size in $P$. palaciosi remains as

270 an interesting possibility.

271 The morphology, physiology and behavior of signal detection and emission organs are

272 frequently influenced by selective pressures not related to the sexual communication function

273 (Niven \& Laughling, 2008; Stöckl et al., 2013; Elgar et al., 2019). Thus, another possible

274 explanation for our results is the existence of additional selective pressures acting in opposite

275 direction to sexual selection or in a more complex way. Although the lantern of adult fireflies is

276 an organ for emitting sexual signals, it can be subject to natural selection (Branham \& Wenzel,

277 2003; Woods et al., 2007; Lewis \& Cratsley, 2008; Stanger-Hall et al., 2018). For example, a

278 study of two Photinus species determined that flashing increases predation risk and metabolic

279 rate (37\% with respect to the basal metabolic rate, even though the experimental setting excluded

280 flight) (Woods et al., 2007). In P. palaciosi it is not known if some predator exerts a similar

281 pressure on signaling fireflies and if this possible effect is related to lantern size. We have made

282 non-systematic observations of several unidentified predators (a grasshopper and species of orb-

283 webb spiders) that capture males during the mating period, although light emission seems

284 irrelevant in prey capture at least for orb-webb spiders.

285

The steeper allometric slope of lantern size in males suggests that the payoff of investing

286 in lanterns proportional to their size may be higher in large males compared to large females.

287 However, the fact that the slope of females is still higher than 0 suggests that large females also

288 benefit from investing in lanterns somewhat proportional to their size. This is consistent with the

289 finding that there is assortative mating in terms of relative lantern size, suggesting some degree 
290 of female-female competition and/or male choice. A likely scenario explaining this pattern may

291 be that among the few females present during a given night, those with larger lanterns could be

292 more detectable to males, or more attractive as the lantern also predicts female size and thus

293 could predict fecundity. In this case, larger females would be the first to mate and, among males

294 competing for these larger females, those with larger lanterns may be detected or selected first by

295 these females. The fact that assortative mating was not found in terms of absolute lantern size but

296 in terms of relative lantern size independently of female body condition is intriguing. At least

297 prior to physical proximity and during the first visual signaling interactions, body size can hardly

298 be assessed by either sex but lantern size could. Relative lantern size may be an honest signal of

299 quality in the case of males as it could show its energetic efficiency independently of body size,

300 or a Fisherian trait, but in the case of females it may be deceiving males if they use it to assess

301 female fecundity as it would not reflect absolute female size or condition, but would still make

302 females with larger lanterns more detectable regardless of their body size. This scenario would

303 not only explain our results in terms of sexual dimorphism, lantern allometry and assortative

304 mating; if males and females throughout the size range of both sexes end up mating, no

305 association between any morphological trait and the probability of being found in copula is

306 expected to arise. Some degree of male mate choice in Photinus fireflies has been suggested

307 before (Lewis et al., 2004a, b), especially since the payoff for males of mating with low

308 fecundity females may be negative when a costly nuptial gift is offered, as it is common in this

309 genus. However, although this still unknown for $P$. palaciosi, female flightlessness as been

310 shown to be associated to loss of spermatophore production in males (South et al., 2011). We are

311 currently investigating if $P$. palaciosi produces nutritious spermatophores. 
313 absolute or relative eye size predicted the probability of being found in copula in either sex. As

314 discussed in the case of lantern size, additional selective pressures affecting eye size and acting

315 in opposite or more complex ways could explain these results (see, for example, Lau \& Meyer-

316 Rochow, 2006). For example, the detection and assessment of visual signals of mate quality

317 (Lewis, 2016; Rosenthal, 2017; Elgar et al., 2019; Stanger-Hall et al., 2018) suggests that the

318 structure and function of the eyes has evolved influenced by intersexual selection (mate choice).

319 However, the eyes are also used to navigate through the habitat, find other resources (food,

320 shelter, etc.) and detect natural enemies and, thus, its evolution is also affected by natural

321 selection (Elgar et al., 2019). As mentioned above, we have observed several predators that

322 capture males during the mating period and could be significant selective pressures on eye size.

323 Interestingly, unlike most species of Photinus, eye size was smaller in males than in females,

324 suggesting that in females selection pressures derived from processes such as female choice,

325 predator avoidance and the choice of perch for mate location, could be important to understand

326 the evolution of eye size. The high variation and allometric slopes of eye size in both sexes imply

327 that this trait is unrelated to body size throughout the body size ranges of both males and

328 females, suggesting that, unlike lanterns, there is little or no selection for larger males or females

329 to invest in eyes proportional to their size. Although having large lanterns and eyes may

330 represent selective advantages (Lloyd, 1966; Demary et al., 2006), a trade-off may restrict the

331 possibility of investing in both functions (structures). It would seem that both sexes favor

332 investing in signaling (lanterns) proportionally to their size, while investment in reception (eyes)

333 is highly variable and independent of body size. 
Firefly populations worldwide are declining and threatening factors vary in importance

335 for different species and regions (Lewis et al., 2020). Although there is a recent and important

336 interest in firefly watching as a tourist attraction, conservation measures and regulation of

337 touristic activities in fireflies "sanctuaries" need to be based on solid scientific information. Light

338 pollution and tourism are considered important threats for the charismatic synchronous species,

339 such as $P$. palaciosi, and these factors have their main impact during the mating period.

340 Unfortunately, mating dynamics have been studied only in a handful of the about 2,000 firefly

341 species described.

342

343 CONCLUSIONS

344 Sexual dimorphism in lantern and eye size, along with allometric slopes of lantern size, and

345 assortative mating in terms of relative lantern size, support not only the hypothesis of intense

346 sexual selection among males of Photinus palaciosi, but also the possibility of subtle

347 mechanisms of sexual selection among females as well. Trade-offs between investment in

348 signaling (lanterns) versus detection (eyes) structures, or with pressures different from sexual

349 selection such as those imposed by predators, are also likely to be important in shaping the

350 evolution of sexual signaling in this species.

351

352 ACKNOWLEDGEMENTS

353 We thank the field assistance of Jaime Camacho, David Xochipiltécatl, Mixtli Crisóstomo Pérez

354 and Israel Hernández. We thank the technical help of Raúl Iván Martínez and Sahid Robles. This 
355 research is part of the doctoral thesis of Tania López-Palafox in the Posgrado en Ciencias

356 Biomédicas (Universidad Nacional Autónoma de México).

357

358 REFERENCES

359 Acle Mena RS, Valverde Sierra ML, Franco Martínez G, Claudio Morales A. 2018.

360

361

362

Sustentabilidad para la preservación del santuario de la luciérnaga en Nanacamilpa Tlaxcala. Pasos, Revista de Turismo y Patrimonio Cultural 16:731-744 DOI

10.25145/j.pasos.2018.16.052.

363

Branham MA, Greenfield MD. 1996. Flashing males win mate success. Nature 381:745-746.

364

365

366

367

368

369

370

371

372

373

374

375

Branham MA, Wenzel JW. 2003. The origin of photic behavior and the evolution of sexual communication in fireflies (Coleoptera: Lampyridae). Cladistics 19:1-22.

Cratsley CK, Lewis SM. 2003. Female preference for male courtship flashes in Photinus ignitus fireflies. Behavioral Ecology 14:135-140.

Cratsley CK, Lewis SM. 2005. Seasonal variation in mate choice of Photinus ignitus fireflies. Ethology 111:89-100.

Crawley MJ. 2013. The R book second edition. 2nd ed. Sussex, UK: Wiley.

Darwin C. 1871. The descent of man and selection in relation to sex. Facsimile of the first edition originally published by John Murray (London, UK). Princeton (USA): Princeton University Press.

Demary K, Michaelidis CI, Lewis SM. 2006. Firefly courtship: behavioral and morphological predictors of male mating success in Photinus greeni. Ethology 112:485-492. 
376 Eberhard WG. 1996. Female control: Sexual selection by cryptic female choice. Princeton NJ:

377 Princeton University Press.

378

379

380

381

382

383

384

385

386

387

388

389

390

391

392

393

394

395

Eberhard WG, Rodríguez RL, Huber BA, Speck B, Miller H, Buzatto BA, Machado G. 1996. Sexual selection and static allometry: the importance of function. The Quarterly Review of Biology 93:207-250.

Elgar MA, Johnson TL, Symonds MR. 2019. Sexual selection and organs of sense: Darwin's neglected insight. Animal Biology 69:63-82 DOI 10.1163/15707563-00001046.

Lau TF, Meyer-Rochow VB. 2006. Sexual dimorphism in the compound eye of Rhagophthalmus ohbai (Coleoptera: Rhagophthalmidae): I. Morphology and ultrastructure. Journal of Asia-Pacific Entomology 9:19-30.

Kilmer JT, Rodríguez RL. 2016. Ordinary least squares regression is indicated for studies of allometry. Journal of Asia-Pacific Entomology 30:4-12.

Lewis S. 2016. Silent sparks: The wondrous world of fireflies. Princeton NJ: Princeton University Press.

Lewis SM, Cratsley CK. 2008. Flash signal evolution, mate choice, and predation in fireflies. Annuual Review of Entomology 53:293-321.

Lewis SM, Cratsley KC, Demaris K. 2004a. Mate recognition and choice in Photinus fireflies. Annales Zoologici Fennici 41:809-821.

Lewis SM, Cratsley KC, Rooney JA. 2004b. Nuptial gifts and sexual selection in Photinus fireflies. Integrative and Comparative Biology 44:234-237. 
396

397

398

399

400

401

402

403

404

405

406

407

408

409

410

411

412

413

414

415

416

417

Lewis SM, Wong CH, Owens ACS, Fallon C, Jepsen S, Thancharoen A, Wu C, de Cook R, Novák M, López-Palafox T, Khoo V, Reed JM. 2020. A global perspective on firefly extinction threats. BioScience 70:157-167 DOI 10.1093/biosci/biz157.

Lloyd JE. 1966. Studies on the flash communication system in Photinus fireflies. Miscellaneous Publications of the Museum of Zoology, University of Michigan 130:1-95.

Lloyd J. 1979. "Sexual selection in luminescent beetles." In Sexual selection and reproductive competition in insects, eds. MS Blum \& NA Blum, pp. 293-342. New York: Academic Press.

Maynard Smith J, Harper DGC. 2003. Animal Signals. Oxford, UK: Oxford University Press.

Moya-Laraño J, Macías-Ordóñez R, Blanckenhorn WU, Fernández-Montraveta C. 2008. Analysing body condition: mass, volume or density? Journal of Animal Ecology 77:1099-1108 DOI 10.1111/j.1365-2656.2008.01433.x

Niven JE Laughlin SB. 2008. Energy limitation as a selective pressure on the evolution of sensory systems. Journal of Experimental Biology 211:1792-1804 DOI 10.1242/jeb.017574.

R Core Team. 2020. $R$ : A language and environment for statistical computing. Vienna, Austria: R Foundation for Statistical Computing. URL https://www.R-project.org/.

R Studio Team. 2016. RStudio: Integrated Development for R. Boston, MA: RStudio, Inc. URL http://www.rstudio.com/.

South A, Stanger-Hall K, Ming-Luen J, Lewis SM. 2011. Correlated

Stanger-Hall KF, Sander Lower SE, Lindberg L, Hopkins A, Pallansch J, Hall DW. 2018. The evolution of sexual signal modes and associated sensor morphology in fireflies 
Stöckl A, Heinze S, Charalabidis A, el Jundi B, Warrant E, Kelber A. 2013. Differential investment in visual and olfactory brain areas reflects behavioural choices in hawk moths. Scientific Reports 6:26041 DOI 10.1038/srep26041.

Thornhill R, Alcock J. 1983. The evolution of insect mating systems. Cambridge MA: Harvard University Press.

Vencl FV, Carlson AD. 1998. Proximate mechanisms of sexual selection in the firefly Photinus 426 pyralis (Coleoptera: Lampyridae). Journal of Insect Behavior 11:191-207.

Warrant E, Dacke M. 2011. Vision and visual navigation in nocturnal insects. Annual Review of Entomology 56:239-254.

Wing SR. 1989. Energetic costs of mating in a flightless female firefly, Photinus collustrans (Coleoptera: Lampyridae). Journal of Insect Behavior 2:841-847.

Woods Jr WA, Hendrickson H, Mason J, Lewis SM. 2007. Energy and predation costs of firefly courtship signals. The American Naturalist 170:702-708 DOI 10.1086/521964.

Zaragoza-Caballero S. 2012. Macrolampis palaciosi sp. nov. (Coleoptera: Lampyridae: Photininae), Tlaxcala, México. Dugesiana 19:117-121. Mirón GM, González-Ramírez M, Gutiérrez-Carranza IG, Cifuentes-Ruiz P, Zurita-García ML. 2020. Luciérnagas del centro de México (Coleoptera: Lampyridae): descripción de 37 especies nuevas. Revista Mexicana de Biodiversidad 91:e913104. DOI 


\section{Figure 1}

Collection sites of Photinus palaciosi in the forest of the municipality of Nanacamilpa de Mariano Arista (Tlaxcala state, México).

All sites were administrated by private eco-touristic businesses. Collection dates and numbers of females and males captured when solitary or in copula in each site are provided. Two copulating females $(*)$ were not included in the analyses because the posture they had after fixation in alcohol prevented obtaining correct measurements. Imagery @ 2020 CNES/AIRBUS, Landsat/Copernicus, Maxar Technologies. Map data @2020 Google, INEGI. Downloaded August 27, 2020.

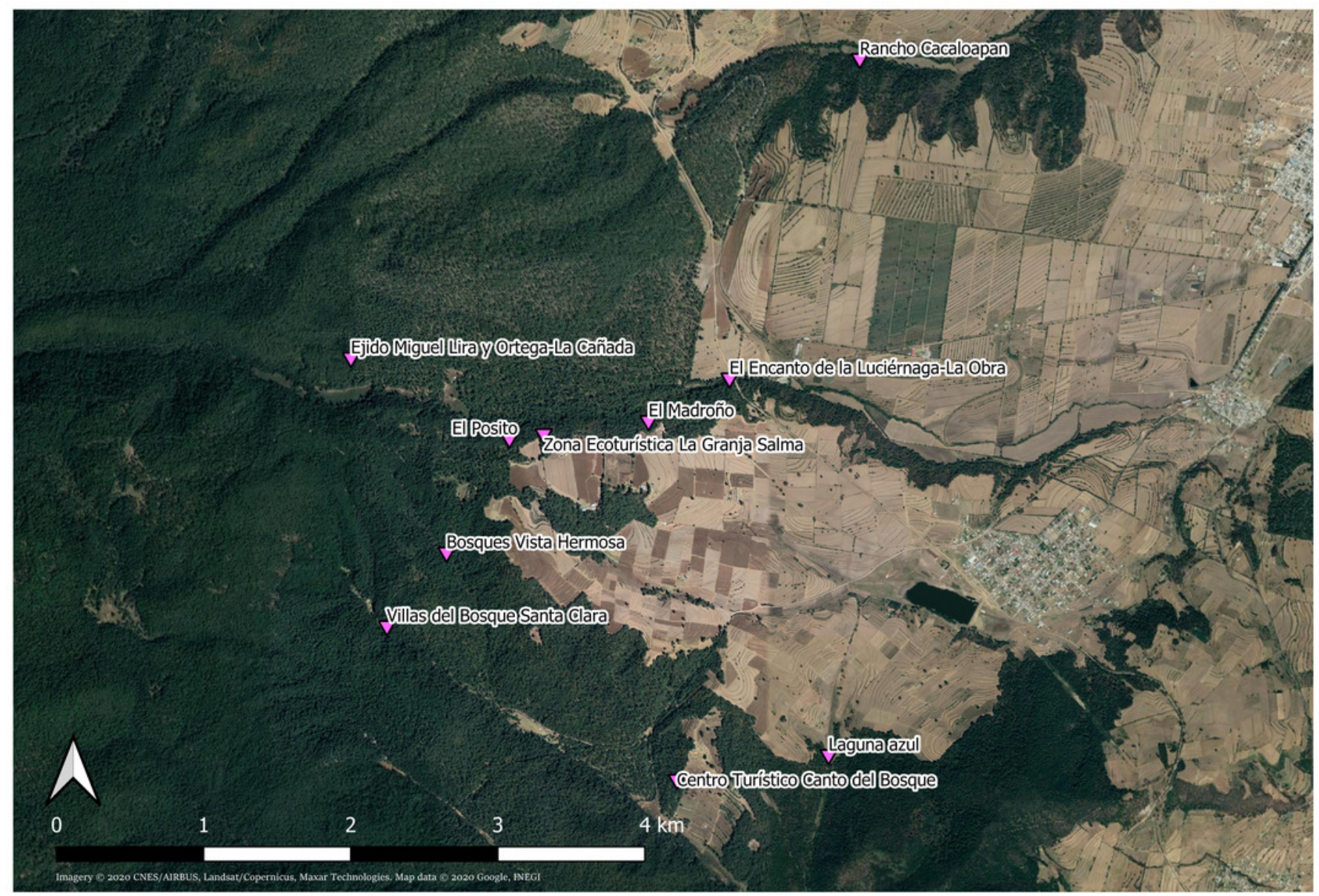




\section{Figure 2}

Measurements performed in males and females of Photinus palaciosi.

(A) Male lantern size area, (B) female lantern size area, (C) maximum eye span, (D) interocular space, (E) male elytra area, (F) female body area and elytra area.
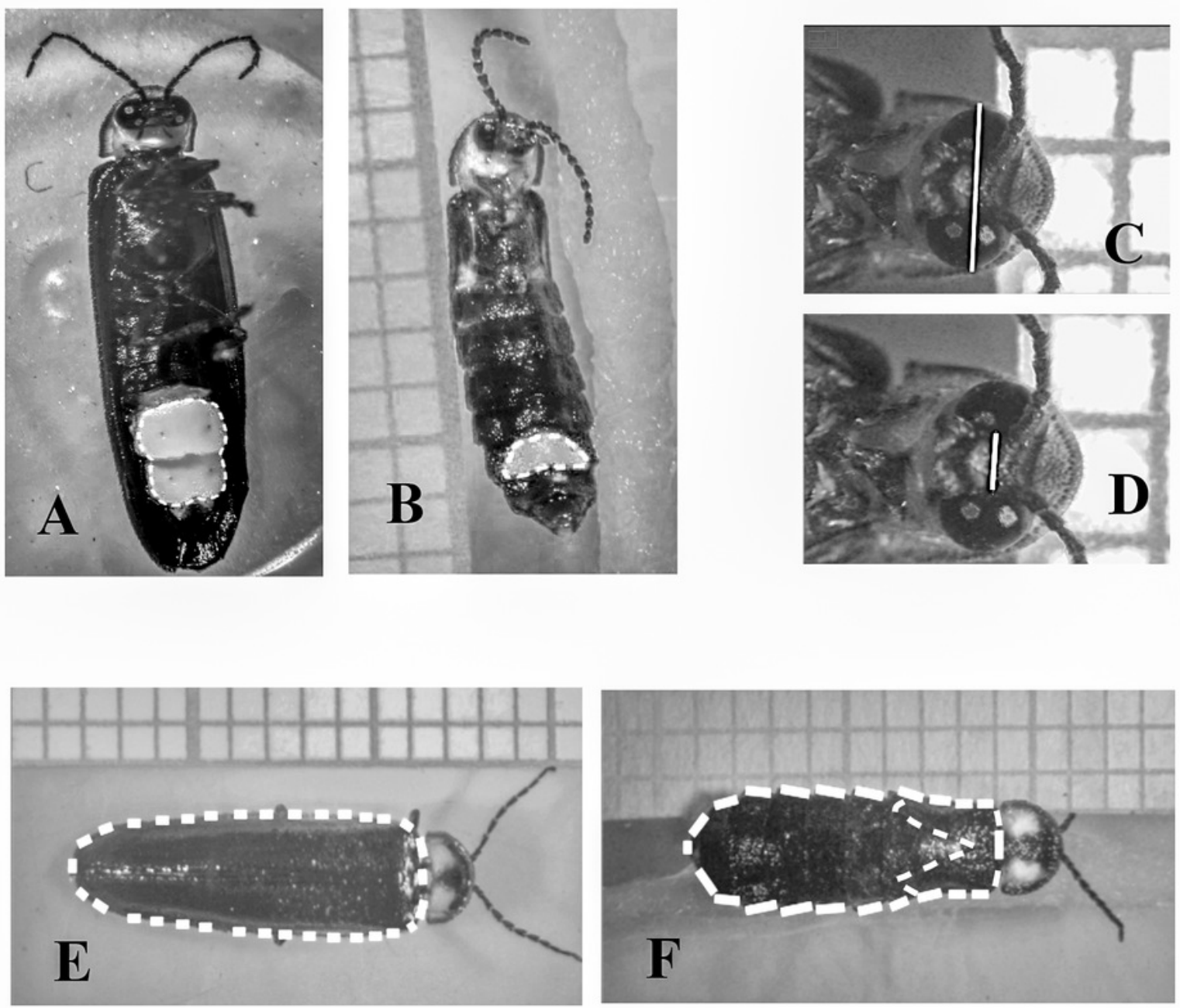


\section{Figure 3}

Static allometry of the synchronous firefly Photinus palaciosi.

(A) Female lantern size relative to body size, (B) female eye size relative to body size, (C) female lantern size relative to elytra size, (D) female eye size relative to elytra size, $(E)$ male lantern size relative to body (elytra) size, (F) male eye size relative to body (elytra) size. Lines in red represent slopes significantly higher than 0 and lines in grey represent slopes non significantly different from 0 (see Table 4 for statistical parameters). 

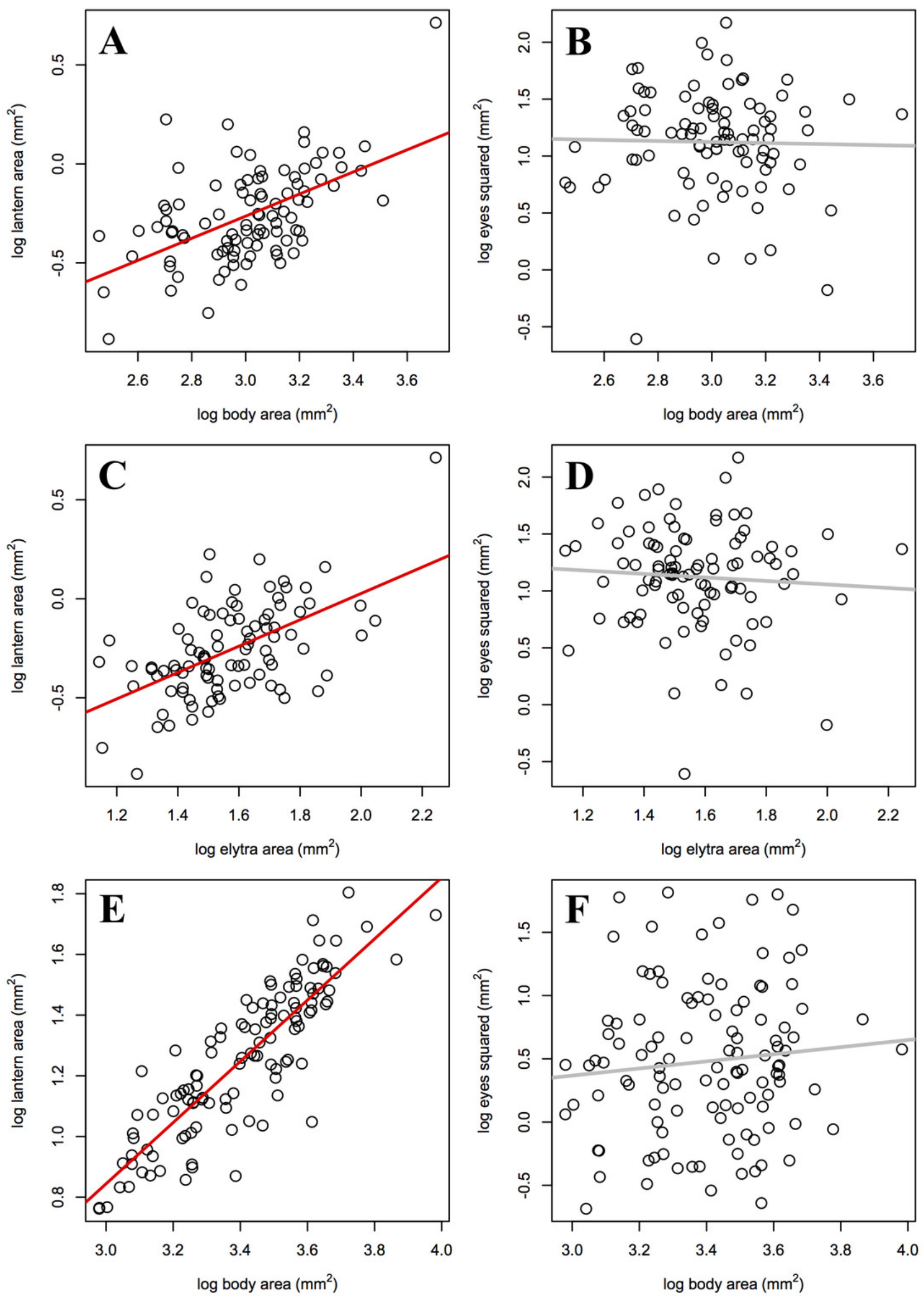
Figure 4

Assortative mating in relative lantern size in the synchronous firefly Photinus palaciosi.

See Table 5 for statistical parameters.

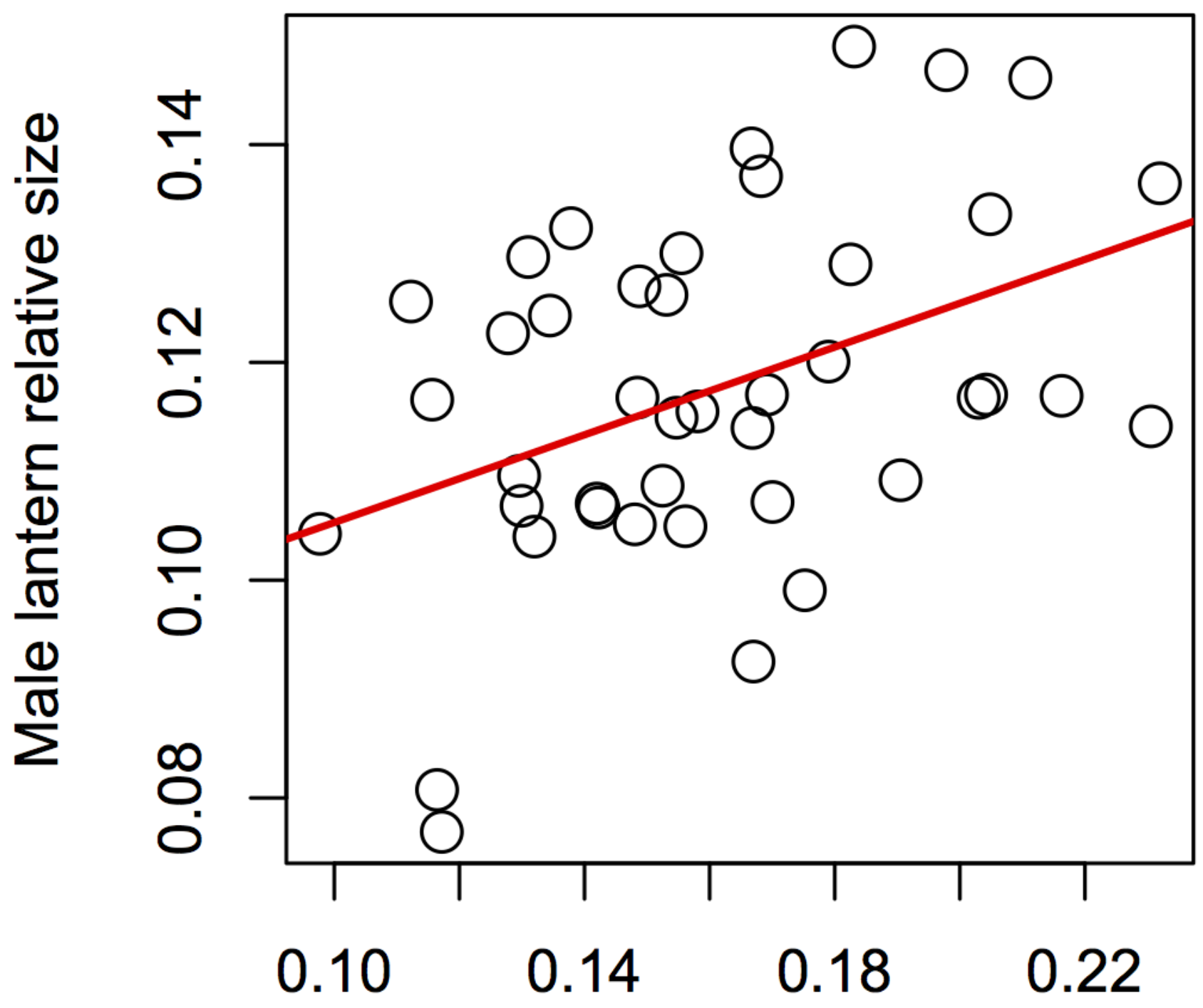

Female lantern relative size 


\section{Table $\mathbf{1}$ (on next page)}

Collection sites of Photinus palaciosi in the forest of the municipality of Nanacamilpa de Mariano Arista (Tlaxcala state, México).

All sites were administrated by private eco-touristic businesses. Collection dates and numbers of females and males captured when solitary or in copula in each site are provided. Two copulating females $(*)$ were not included in the analyses because the posture they had after fixation in alcohol prevented obtaining correct measurements. 


\begin{tabular}{lccccc}
\multicolumn{1}{c}{ Site } & Date & $\begin{array}{c}\text { Solitary } \\
\text { females }\end{array}$ & $\begin{array}{c}\text { Females } \\
\text { in copula }\end{array}$ & $\begin{array}{c}\text { Solitary } \\
\text { males }\end{array}$ & $\begin{array}{c}\text { Males in } \\
\text { copula }\end{array}$ \\
\hline 1. Centro Turístico Canto del Bosque & $29 / 06$ & 10 & 1 & 15 & 1 \\
\hline 2. Laguna azul & $30 / 06$ & 6 & 7 & 9 & 7 \\
\hline 3. El Madroño & $1 / 07$ & 9 & 2 & 12 & 2 \\
\hline 4. Zona Ecoturística La Granja Salma & $2 / 07$ & 8 & 5 & 11 & 5 \\
\hline 5. El Posito & $3 / 07$ & 6 & $4 *$ & 11 & 4 \\
\hline 6. Rancho Cacaloapan & $4 / 07$ & 2 & $5 *$ & 8 & 5 \\
\hline 7. Ejido Miguel Lira y Ortega-La Cañada & $5 / 07$ & 7 & 5 & 2 & 5 \\
\hline 8. Villas del Bosque Santa Clara & $6 / 07$ & 3 & 3 & 0 & 3 \\
\hline 9. Bosques Vista Hermosa & $8 / 07$ & 0 & 8 & 1 & 8 \\
\hline 10. El Encanto de la Luciérnaga-La Obra & $14 / 07$ & 0 & 4 & 0 & 4 \\
\hline
\end{tabular}




\section{Table 2 (on next page)}

Results of five models evaluating association between probability of being collected copulating rather than alone and trait size.

Absolute trait size in males (A), females (B), trait size relative to body (elytra) size in males (C), trait size relative to body size in females (D), and trait size relative to elytra size in females (E) in the synchronous firefly Photinus palaciosi. Parameters from initial models are presented since backwards stepwise simplification resulted in removal of all explanatory variables in all models. 
1

$\begin{array}{llll}\text { Fixed Effects } & \boldsymbol{\beta} \pm \mathrm{SE} & \mathbf{Z} & \mathbf{P}_{\mathrm{Z}}\end{array}$

A) Absolute size - males

Body (elytra)

$\begin{array}{lll}-0.087 \pm 0.166 & -0.52 & 0.602\end{array}$

Lantern

$\begin{array}{lll}-0.517 \pm 1.371 & -0.38 & 0.706\end{array}$

Eyes $^{2}$

$0.758 \pm 0.827 \quad 0.92 \quad 0.360$

Body x Lantern

$\begin{array}{lll}0.029 \pm 0.032 & 0.91 & 0.364\end{array}$

Body x Eyes ${ }^{2}$

$\begin{array}{lll}-0.005 & \pm 0.053 \quad-0.09 & 0.931\end{array}$

Lantern x Eyes ${ }^{2}$

$-0.149 \pm 0.392$

$-0.38$

0.704

B) Absolute size-females

Body (elytra)

$\begin{array}{lll}-0.163 \pm 0.278 & -0.59 & 0.557\end{array}$

Lantern

$\begin{array}{lll}-9.260 \pm 7.539 & -1.23 & 0.219\end{array}$

Eyes $^{2}$

$\begin{array}{lll}0.119 \pm 0.929 & 0.13 & 0.898\end{array}$

Body x Lantern

$\begin{array}{lll}0.355 \pm 0.299 & 1.19 & 0.235\end{array}$

Body x Eyes ${ }^{2}$

$\begin{array}{lll}-0.008 \pm 0.046 & -0.17 & 0.864\end{array}$

Lantern x Eyes ${ }^{2}$

$0.036 \pm 1.149$

$0.03 \quad 0.975$

C) Relative size - males

Body (elytra)

$0.133 \pm 0.316 \quad 0.42 \quad 0.673$

Lantern

$44.192 \pm 98.546$

0.45

0.654

Eyes $^{2}$

$62.479 \pm 50.495 \quad 1.24 \quad 0.216$

Body x Lantern

$\begin{array}{lll}-0.540 \pm 2.664 & -0.20 & 0.839\end{array}$

Body x Eyes ${ }^{2}$

$-0.663 \pm 0.800 \quad-0.83 \quad 0.408$

Lantern x Eyes ${ }^{2}$

$-349.314 \pm 364.564$

$-0.96 \quad 0.338$

D) Relative size - body females

Body

$\begin{array}{lll}0.189 \pm 0.270 & 0.70 & 0.484\end{array}$

Lantern

$12.014 \pm 147.610 \quad 0.08 \quad 0.935$ 


\begin{tabular}{|c|c|c|c|}
\hline Eyes $^{2}$ & $19.705 \pm 23.523$ & 0.84 & 0.402 \\
\hline Body x Lantern & $-0.836 \pm 5.693$ & -0.15 & 0.883 \\
\hline Body x Eyes ${ }^{2}$ & $-0.752 \pm 0.804$ & -0.93 & 0.350 \\
\hline Lantern $x$ Eyes $^{2}$ & $-136.556 \pm 312.171$ & -0.44 & 0.662 \\
\hline \multicolumn{4}{|c|}{ E) Relative size - elytra females } \\
\hline Elytra & $-0.102 \pm 0.254$ & -0.402 & 0.688 \\
\hline Lantern & $-51.635 \pm 41.787$ & -1.24 & 0.217 \\
\hline Eyes $^{2}$ & $-1.407 \pm 5.306$ & -0.26 & 0.791 \\
\hline Body x Lantern & $1.444 \pm 1.486$ & 0.97 & 0.331 \\
\hline Body x Eyes ${ }^{2}$ & $-0.092 \pm 0.177$ & -0.2 & 0.605 \\
\hline Lantern x Eyes ${ }^{2}$ & $20.733 \pm 20.471$ & 1.013 & 0.311 \\
\hline
\end{tabular}

2 


\section{Table 3(on next page)}

Comparison of the morphological measurements of male and female Photinus palaciosi fireflies.

Median, mean [minimum value - maximum value] are given for each trait. 
1

\begin{tabular}{cccc} 
& Females & Males & Linear model p [ $\left.\mathbf{F}_{\mathbf{1 , 2 0 4}}\right]$ \\
\hline Body area & $20.43,20.78$ & $30.92,30.73$ & $<0.001$ \\
$\left(\mathrm{~mm}^{2}\right)$ & {$[11.66-40.69]$} & {$[19.68-53.64]^{\mathrm{a}}$} & {$[152.4]$} \\
Elytra area & $4.65,4.90$ & $30.92,30.73$ & $<0.001$ \\
$\left(\mathrm{~mm}^{2}\right)$ & {$[3.13-9.43]$} & {$[19.68-53.64]^{\mathrm{a}}$} & {$[1493]$} \\
Lantern area & $0.74,0.79$ & $3.52,3.59$ & $<0.001$ \\
$\left(\mathrm{~mm}^{2}\right)$ & {$[0.41-2.04]$} & {$[2.14-6.08]$} & {$[925.8]$} \\
Lantern relative & $3.65,3.91$ & $11.69,11.70$ & $<0.001$ \\
size x100 & {$[2.84-8.38]$} & {$[7.69-15.09]$} & {$[2095]$} \\
Eyes $^{2}$ & $3.29,3.37$ & $1.56,1.93$ & $<0.001$ \\
$\left(\mathrm{~mm}^{2}\right)$ & {$[0.54-8.77]$} & {$[0.50-6-14]$} & {$[59.27]$} \\
Eyes relative & $15.58,17.10$ & $5.17,6.51$ & $<0.001$ \\
size x100 & {$[2.71-41.40]$} & {$[1.49-25.58]$} & {$[141]$} \\
\hline
\end{tabular}

3 Notes.

$4{ }^{a}$ Elytra area was used as the main estimate of male body size.

$5{ }^{\mathrm{b}}$ Relative size is multiplied by 100 in order to illustrate more decimal points.

6 


\section{Table 4(on next page)}

Allometric slopes of lantern and eye size for females and males of the firefly Photinus palaciosi.

Two proxies of body size were used for females, body and elytra area, and one, body (=elytra) area, for males. $\mathrm{m}=$ allometric slope value [95\% Bootstrap confidence interval]. Parameters of significant correlations in italics. 


\section{Lantern $\left(\mathrm{mm}^{2}\right) \quad \operatorname{Eyes}^{2}\left(\mathbf{m m}^{2}\right)$}

\section{Females}

Body area

$m=0.56$

$\mathrm{m}=-0.04$

$\left(\mathrm{mm}^{2}\right)$

[0.32, 0.78]

$[-0.51,0.37]$

$R^{2}=0.28, p<0.001$

$\mathrm{R}^{2}=0.01, \mathrm{p}=0.829$

Elytra area

$$
m=0.67
$$

$\mathrm{m}=-0.15$

$\left(\mathrm{mm}^{2}\right)$

$$
\text { [0.39, 0.94] }
$$

[-0.68, 0.30]

$R^{2}=0.30, p<0.001$

$\mathrm{R}^{2}=0.01, \mathrm{p}=0.524$

Males

Body (=Elytra)

$$
\begin{gathered}
m=1.01 \\
{[0.91,1.11]} \\
R^{2}=0.74, p<0.001
\end{gathered}
$$$$
\mathrm{m}=0.28
$$

$\left(\mathrm{mm}^{2}\right)$$$
\text { [-0.21, 0.77] }
$$

$\mathrm{R}^{2}<0.01, \mathrm{p}=0.297$ 


\section{Table 5 (on next page)}

Correlation of the morphological traits of males and females found in copula in Photinus palaciosi fireflies.

Two versions of lantern and eyes relative size were calculated for females, one using body area and other using elytra area. Significant correlations in italics. 
1

\begin{tabular}{cccc}
$\begin{array}{c}\text { Male vs Female } \\
\text { trait }\end{array}$ & Absolute Size & $\begin{array}{c}\text { Relative Size } \\
\text { (female body) }\end{array}$ & $\begin{array}{c}\text { Relative Size } \\
\text { (female elytra) }\end{array}$ \\
\hline Body & $\mathrm{R}^{2}=0.024$ & --- & --- \\
$\mathrm{p}=0.851$ & --- & --- \\
Elytra & $\mathrm{R}^{2}=0.008$ & --- & --- \\
& $\mathrm{p}=0.258$ & --- & --- \\
Lantern & $\mathrm{R}^{2}=0.011$ & $\mathrm{R}^{2}=0.021$ & $R^{2}=0.153$ \\
& $\mathrm{p}=0.236$ & $\mathrm{p}=0.176$ & $\mathrm{p}=0.006$ \\
Eyes $^{2}$ & $\mathrm{R}=0.010$ & $\mathrm{R}^{2}=0.020$ & $\mathrm{R}^{2}=0.019$ \\
& $\mathrm{p}=0.443$ & $\mathrm{p}=0.676$ & $\mathrm{p}=0.642$ \\
\hline
\end{tabular}

2

3 